\title{
Article \\ A Case Study Investigating Mental Wellbeing of University Academics during the COVID-19 Pandemic
}

\author{
Larisa M. Dinu ${ }^{1,+}{ }^{\text {, Eleanor J. Dommett }}{ }^{1,2, *,+}{ }^{1}$, Ardic Baykoca ${ }^{1}$, Kosha J. Mehta ${ }^{3}$, Sally Everett ${ }^{4}$, \\ Juliet L. H. Foster ${ }^{1}$ and Nicola C. Byrom ${ }^{1}$
}

1 Department of Psychology, Institute of Psychology, Psychiatry and Neuroscience, King's College London, London SE5 8AF, UK; larisa.dinu@kcl.ac.uk (L.M.D.); ardic.1.baykoca@kcl.ac.uk (A.B.); juliet.foster@kcl.ac.uk (J.L.H.F.); Nicola.byrom@kcl.ac.uk (N.C.B.)

2 Centre for Technology Enhanced Learning, King's College London, London SE1 9NH, UK

3 Centre for Education, Faculty of Life Sciences and Medicine, King's College London, London SE1 1UL, UK; kosha.mehta@kcl.ac.uk

4 Department of Marketing, King's Business School, King's College London, London WC2B 4BG, UK; sally.everett@kcl.ac.uk

* Correspondence: eleanor.dommett@kcl.ac.uk; Tel.: +44-207-848-6928

+ Indicates joint first authorship.

Citation: Dinu, L.M.; Dommett, E.J.; Baykoca, A.; Mehta, K.J.; Everett, S.; Foster, J.L.H.; Byrom, N.C. A Case Study Investigating Mental Wellbeing of University Academics during the COVID-19 Pandemic. Educ. Sci. 2021, 11, 702. https://doi.org/10.3390/ educsci11110702

Academic Editor: Kelum Gamage

Received: 2 October 2021

Accepted: 22 October 2021

Published: 2 November 2021

Publisher's Note: MDPI stays neutral with regard to jurisdictional claims in published maps and institutional affiliations.

Copyright: (c) 2021 by the authors. Licensee MDPI, Basel, Switzerland. This article is an open access article distributed under the terms and conditions of the Creative Commons Attribution (CC BY) license (https:// creativecommons.org/licenses/by/ $4.0 /)$.

\begin{abstract}
COVID-19 has impacted Higher Education worldwide. While several studies have examined the effects of the pandemic on students, few have addressed its impact on academic staff. Here, we present both survey $(n=89)$ and interview $(n=12)$ data highlighting the pandemic-induced effects on academics from various disciplines and career stages. Data was collected between May and September 2020, aiming to capture and understand the immediate effects of the U.K. lockdown on the academics examining demographic and employment factors, digital abilities and confidence, and mental wellbeing. Analyses revealed that most academics were satisfied with the support they received from the university and colleagues, and they had adequate equipment and space at home to work. However, half incurred additional financial costs to maintain access to technology and many felt an altered relationship with the university. There were discrepancies in digital abilities and confidence according to employment status, age, faculty, and social identity as an academic. Teaching workload did not increase across the board, rather seniority predicted increases. Levels of wellbeing were low but were not significantly predicted by workload increase or abilities and confidence in working digitally as might have been expected. Stronger social identity as an academic may predict higher mental wellbeing with qualitative data suggesting teamwork and collegiate activities helped. Furthermore, interviewees identified several positive aspects to working remotely. These findings suggest universities should consider carefully how to support all staff to work digitally and consider flexible working post-pandemic.
\end{abstract}

Keywords: digital capabilities; online teaching; social identity; wellbeing

\section{Introduction}

COVID-19 has deeply impacted Higher Education [1]. While research has considered the effects of the pandemic on students [2-8], few studies have considered the impact on academics $[9,10]$. This gap is problematic because university academics not only provide education but are also at the forefront of the pastoral and academic support provision for students. Moreover, even prior to the pandemic, concerns had been raised about academic staff wellbeing, with many reported as being at risk of burnout [11] and a recent survey finding that $43 \%$ of academic staff exhibited symptoms of at least a mild mental disorder; this is almost twice the figure for the general population [12]. The pandemic induced sudden changes in the mode of working, switching to online education and homeworking, affecting both the personal and professional lives of the academics has the potential to have worsened the situation further. 
Anecdotal evidence suggests that the abrupt transition to online education increased teaching workloads for academics. In the U.K. there were two critical periods in 2020-the period following the closure of universities' premises (March-April 2020) and the summer period (July-August 2020). During the former, academics were forced to respond quickly to the pandemic and offer prompt alternatives for face-to-face teaching and assessment. Thus, academics were required to provide timely solutions while they experienced a loss of usual resources and support provided through campus services (e.g., IT support) and other key support, such as childcare. In the latter period, academics focused on developing teaching suitable for the online delivery for the next academic year $(2020 / 2021)$ when it became apparent a return to face-to-face teaching was not viable.

Online education is not new, but the accelerated shift to a fully online provision requires significant adjustment of teaching. Online teaching demands specific pedagogical knowledge and involves redesigning and reorganizing the teaching content to make it suitable for a different environment [13]. While motivation to use digital technology in teaching is high, few academics feel that they have the time to develop the necessary digital skills which underpin online education [14]. Further, the constraints experienced by students in using digital technology, such as challenges with digital devices and internet connectivity, would be equally applicable to academics when preparing for and delivering online learning without access to campus facilities [15]. In this context, the shift online might be expected to have been a source of considerable stress for academics.

It is also likely that the distress experienced by students, due to the pandemic, would have had a knock-on effect on the workload and emotional strain for some academics. Academics are often the first to respond to students' mental health concerns [16,17]. Despite this, research suggests that the emotional investment and time spent in supporting student mental health is not adequately recognized by universities and support for academics is limited [16,18]. Notably, in providing support to the students, the mental health and wellbeing of academics is often ignored [19]. Usually, the time spent in supporting students is unaccounted for and comes at a cost to other responsibilities, including research, which are assessed in performance reviews and count towards academic promotion [20]. This impact is greater for female academics than their male counterparts [21].

Teaching and other student-facing responsibilities were not the only activities impacted by the pandemic; some academics were involved in COVID-related research whilst others experienced a suspension of research activities, resulting in a loss of research funding or forcing plans to be re-arranged and affecting outputs that are essential for promotion and other forms of recognition. Disruption to these core activities of academics is likely to have impacted on their professional identity, which is known to be affected by multiple identities (e.g., as a teacher, researcher, discipline expert, gender, and personal roles such as parent [22]). Furthermore, professional identity in academics contributes to their sense of belonging [23], which could also be disrupted by drastic changes in work activities. Homeworking can create challenges for organizational belonging [24]. Both social identity $[25,26]$ and sense of belonging [27] can impact on mental wellbeing indicating that these changes to academic working could affect mental wellbeing in staff.

Given the previous concerns raised about staff wellbeing prior to the pandemic and the clear potential for COVID-induced changes to academic roles and responsibilities to negatively impact on staff mental wellbeing, we aimed to better understand the impact of COVID on staff using a combination of quantitative and qualitative research. Specifically, we aimed to better understand what factors contributed to (i) digital capabilities, (ii) increased workload, and (iii) mental wellbeing.

\section{Materials and Methods}

\subsection{Design and Procedure}

This study adopted a mixed methods approach, with two phases of data collection. During the first phase (12 May-23 June 2020) data was collected from academic staff at a large Russell group London-based university using an anonymous online survey. The 
survey was advertised via institutional research recruitment circulars, the university's virtual learning environment and through program administrators. It took approximately $25 \mathrm{~min}$ to complete, and participants were asked to provide an email address at the end, held separately from their survey data, if they would be willing to be interviewed about online education during the pandemic. The interviews formed the second phase of data collection and were held in August and September 2020. Interviews were approximately $40 \mathrm{~min}$. All participants completing the survey had the option of being entered into a prize draw for $£ 50$ vouchers and those completing interviews were given a $£ 10$ voucher honorarium. This research was approved by the institutional ethical review committee (MRA-19/20-18209).

\subsection{Survey Measures}

\subsubsection{Demographic Factors}

To characterize the sample and understand what demographic factors might impact workload and wellbeing the first part of the survey assessed age, gender, ethnicity, and disability. Given that one of the major challenges facing all workforces during the pandemic was the closure of school and childcare facilities, we also assessed caring responsibilities. Staff were asked to indicate if they had caring responsibilities and for whom (e.g., preschool age child). They were then asked to indicate if these responsibilities had increased during COVID and whether any increase had impacted negatively on their work. They were also asked to indicate the how many hours were spent caring in a day. A final open question on caring asked staff to explain how their work has been affected by the increased caring responsibilities. Demographic characteristics of the sample are shown in Table 1.

Table 1. Teaching staff demographic information.

\begin{tabular}{ccc}
\hline Demographic & Survey (\%) & Interview (\%) \\
\hline Age range (years) & $17(19)$ & - \\
$26-35$ & $32(36)$ & - \\
$36-45$ & $20(23)$ & - \\
$46-55$ & $19(22)$ & - \\
$56-70$ & $56(64)$ & $6(50)$ \\
Gender & $32(36)$ & $6(50)$ \\
Female & $45(51)$ & - \\
Male & $34(39)$ & - \\
Ethnicity & $9(10)$ & - \\
White British & $63(75)$ & - \\
White non-British & $21(25)$ & - \\
BAME ${ }^{+}$ & & - \\
Disability & $50(56)$ & - \\
No & $39(44)$ & \\
Yes & Caring Responsibilities &
\end{tabular}

${ }^{\dagger}$ Including Black or Black British, Asian or Asian British, Chinese or Chinese British, and mixed background ethnicities

\subsubsection{Employment Factors}

Details of employment were also collected with staff indicating the following about their current employment: (i) status as full or part time (with full-time equivalent); (ii) seniority of academic position (e.g., teaching fellow, professor); (iii) faculty and type of program they teach on (e.g., natural science and undergraduate); (iv) contract type (e.g., fixed term). Table 2 provides a summary of the employment characteristics of the sample. 
Table 2. Staff employment information.

\begin{tabular}{|c|c|c|}
\hline Employment & Survey $(n=89)$ & Interview $(n=12)$ \\
\hline \multicolumn{3}{|l|}{ Employment status } \\
\hline Full-time & $67(75)$ & - \\
\hline Part-time & $22(25)$ & - \\
\hline \multicolumn{3}{|l|}{ Contract type } \\
\hline Fixed term & $20(23)$ & - \\
\hline Open-ended & $67(76)$ & - \\
\hline Casual ${ }^{\dagger}$ & $1(1)$ & - \\
\hline \multicolumn{3}{|l|}{ Seniority } \\
\hline Teaching Fellow & $18(21)$ & $3(27)$ \\
\hline Lecturer & $27(32)$ & $4(36)$ \\
\hline Senior Lecturer & $17(20)$ & 0 \\
\hline Reader & $11(13)$ & $2(18)$ \\
\hline Professor & $11(13)$ & $2(18)$ \\
\hline \multicolumn{3}{|l|}{ Teaching level } \\
\hline Undergraduate & $60(68)$ & - \\
\hline Taught postgraduate & $28(32)$ & - \\
\hline \multicolumn{3}{|l|}{ Faculty } \\
\hline Arts \& Humanities & $9(10)$ & $1(8)$ \\
\hline Social Sciences \& Economics & $23(26)$ & $4(33)$ \\
\hline Medicine \& Allied healthcare subjects & $47(53)$ & $5(42)$ \\
\hline Natural \& Mathematical Sciences & $9(10)$ & $2(17)$ \\
\hline
\end{tabular}

${ }^{\dagger}$ Omitted from further group analysis.

Table 3 indicates the employment characteristics of staff indicating a range of staff contributed to the dataset.

Table 3. Regression coefficients for overall digital confidence and ability.

\begin{tabular}{|c|c|c|c|c|c|c|c|c|}
\hline \multirow{3}{*}{$\begin{array}{c}\text { IVs } \\
\text { Gender }\end{array}$} & \multicolumn{4}{|c|}{ Digital Confidence } & \multicolumn{4}{|c|}{ Digital Ability } \\
\hline & \multirow{2}{*}{$\frac{\mathbf{b}}{0.90}$} & \multicolumn{2}{|c|}{$95 \%$ CI } & \multirow{2}{*}{$\begin{array}{c}\text { Sig } \\
0.873\end{array}$} & \multirow{2}{*}{$\begin{array}{c}\mathbf{b} \\
-0.03\end{array}$} & \multicolumn{2}{|c|}{$95 \%$ CI } & \multirow{2}{*}{$\begin{array}{c}\text { Sig } \\
0.996\end{array}$} \\
\hline & & -50.89 & 27.06 & & & -11.12 & 11.06 & \\
\hline White non-British ${ }^{1}$ & -1.65 & -10.32 & 12.11 & 0.746 & 0.76 & -9.35 & 10.87 & 0.881 \\
\hline BAME $^{1}$ & -7.12 & -11.82 & 8.51 & 0.287 & -4.57 & -18.55 & 9.42 & 0.516 \\
\hline Age & -7.21 & -20.38 & 6.15 & $<0.01$ & -5.41 & -10.42 & -0.40 & $<0.05$ \\
\hline Disability & 6.38 & -11.98 & -2.44 & 0.242 & 8.05 & -3.13 & 19.23 & 0.155 \\
\hline Caring & 2.09 & -4.43 & 17.19 & 0.649 & -3.59 & -13.05 & 5.88 & 0.451 \\
\hline Status & 14.29 & -7.08 & 11.26 & $<0.05$ & 4.80 & -7.54 & 17.15 & 0.439 \\
\hline Contract type & -1.84 & 2.61 & 25.98 & 0.743 & -0.70 & -12.53 & 11.13 & 0.906 \\
\hline Seniority & 1.19 & -13.06 & 9.37 & 0.532 & 3.22 & -0.81 & 7.24 & 0.115 \\
\hline Teaching level & 9.82 & -2.61 & 4.99 & 0.039 & 4.11 & -5.56 & 13.78 & 0.398 \\
\hline Arts/Humanities ${ }^{2}$ & 12.09 & 0.53 & 19.11 & 0.137 & 8.74 & -8.22 & 25.71 & 0.306 \\
\hline Social Sci.\&Econ. ${ }^{2}$ & 0.71 & -3.95 & 28.13 & 0.891 & 5.88 & -4.92 & 16.68 & 0.280 \\
\hline Natural/Maths Sci. ${ }^{2}$ & 21.58 & -9.67 & 11.09 & $\leq 0.01$ & 17.36 & 1.39 & 33.32 & $<0.05$ \\
\hline Social identity & 0.72 & 5.63 & 37.54 & $\leq 0.001$ & 0.57 & 0.13 & 1.01 & $<0.05$ \\
\hline Safe space to work & 3.57 & 0.30 & 1.14 & 0.553 & 0.31 & -12.13 & 12.75 & 0.960 \\
\hline Equipped space & 1.92 & -8.41 & 15.55 & 0.722 & 0.27 & -10.32 & 10.86 & 0.959 \\
\hline
\end{tabular}

Digital confidence: $\mathrm{R} 2=0.52, \mathrm{~F}(16,55)=3.69, p<0.001$; Digital ability: $\mathrm{R} 2=0.37, \mathrm{~F}(16,57)=2.10, p=0.021 .{ }^{1}$ Reference value, White British;

2 Reference value, Medical Sciences.

Related to employment, the 11-item Social Identity scale [28] was used to measure how much of the participants' perceived identity was linked to them being academic at the specific university to access constructs around identity and belonging. Items, such as "In a group of people at my university, I really feel that I belong", were positively worded and were ranked on a 7-point Likert scale (strongly disagree-strongly agree). Items were summed to calculate a total score (range 11-77). Higher scores indicate a closer link between social identity and being an academic at the specific university. This scale showed 
excellent reliability ( $\alpha=0.87$ ). Staff were also asked to indicate whether their relationship with the university had changed since the pandemic begun $(\mathrm{Y} / \mathrm{N})$, followed by an open question asking them to elaborate on their response to the $\mathrm{Y} / \mathrm{N}$ question.

\subsubsection{Technology and Digital Capabilities}

Given the extensive reliance on digital tools and remote working, staff were asked about access to software and hardware prior to the pandemic and during it. They were also asked about whether they had incurred additional financial costs for work-based activities (e.g., purchasing of devices or internet costs). Workspace was also investigated by asking about whether staff had a safe space to work at home relatively undisturbed and whether they had an adequately equipped space at home. Finally, they were asked whether the university had offered to provide any necessary devices or software. The JISC digital capabilities tool was used to assess digital abilities and digital confidence. Six digital capabilities domains were assessed: (i) digital proficiency, (ii) information, data and media literacies, (iii) digital communication, collaboration and participation, (iv) digital creation, problem-solving and innovation, (v) digital learning and development, (vi) digital identity and wellbeing. For each domain, participants ticked off their abilities from a pre-defined list. Each domain is composed of 10 items except for the 'Digital communication, collaboration and participation' which has 9 items. Six ability scores were calculated, scaling to obtain a percentage from $1 \%$ to $98.6 \%$, as advised by JISC. Digital confidence was assessed within each domain using a $0-100 \%$ scale.

\subsubsection{COVID-Related Education Changes}

To provide some context to the findings, the survey asked questions about the shift to online learning. Staff were asked to indicate from a list (with an 'other' option) the changes to teaching that they have experienced, e.g., I have made my small group teaching available online (e.g., using MS Teams or Zoom). This was followed by an open question asking staff to indicate the most and least effective approaches and explain their reasoning. They were also asked to identify changes to assessment types (e.g., change to exam format) and respond to an open question about the support that was made available to them to set up alternative assessment. Two further open questions were asked about the most positive and most challenging aspects of teaching during COVID. Finally, to provide an indication of workload changes relating to teaching, staff were asked to indicate the proportion of their time dedicated to teaching prior to and during COVID-19.

\subsubsection{Mental Wellbeing}

The 7-item Short Warwick-Edinburgh Mental Wellbeing Scale (SWEMWBS) was used to measure mental wellbeing (Stewart-Brown et al., 2009). Items were positively worded and were scored on a 5-point Likert scale. Total raw scores were calculated by summing all items. Raw scores were then converted to metric scores (range 7-35; Stewart-Brown et al., 2009). This scale showed good reliability $(\alpha=0.79)$.

\subsection{Interview Schedule}

Semi-structured interviews were completed with a subsample $(n=12)$ to further understand how academics had coped and were coping with the pandemic-induced sudden transition to online teaching. We aimed to understand whether the academics had an adequate environment for working, whether they had received adequate support from their line managers, their departments or the university, and note their experiences with online teaching and online assessment. In addition, we wanted to understand if and how their mental wellbeing had been affected during the pandemic and whether the pandemic had forced them to change their career plans. Interview questions were initially developed by four teaching academics, who themselves had experienced the rapid transition to online learning. In addition, following the preliminary analyses of the quantitative data, we added several questions on digital skills to understand the skills the academics used and 
developed when switching to the online teaching and learning mode. The final interview schedule was divided into four sections: their working environment during the pandemic (e.g., space, equipment, and challenges); teaching and assessment experiences during the pandemic including digital needs; and support and wellbeing.

\subsection{Data Analysis}

Quantitative survey data were analyzed using SPSS. Demographic and employment factors, as well as digital capabilities and mental wellbeing constructs were examined via descriptive statistics. Additionally, based on previous research or anecdotal reports during the pandemic several planned exploratory analyses were conducted. Caring responsibilities were compared between demographic groups using Pearson's Chi-Square. Social identity was compared between different employment and demographic groups using either independent t-tests or One-Way ANOVAs. Linear regression analysis was used to ascertain whether demographic, employment factors or home working arrangements predicted digital abilities and confidence. Similarly, linear regression was used to examine whether demographic, employment factors, home working arrangements, digital abilities and confidence predicted change in workload during the pandemic. Finally, linear regression was used to determine whether social identity, workload change, digital ability and confidence could predict mental wellbeing.

The free-text answers from the eight open questions, which were answered by between $60 \%$ and $100 \%$ of survey respondents, and the interview data were initially analyzed separately. Thematic analysis was completed by three researchers. Survey responses were reviewed and coded independently by two researchers. This coding was reviewed by a third coder. Interviews were transcribed automatically using Microsoft Stream, checked, and corrected by two researchers. One interview was coded independently by three researchers. The remaining 11 interviews were double coded by two of these researchers. Finally, reviewing codes from the survey and interviews in parallel, themes from these two avenues were integrated. The analysis took a realist approach and was completed at a semantic level, with themes identified from the explicit meanings of the participants responses [29]. An inductive, bottom-up approach was adopted to identify themes and patterns within the dataset. Coding was discussed between the team at multiple points to clarify themes and avoid individual biases [30].

\section{Results}

Given the mixed methods approach and the common analysis adopted for both open survey responses and interview data, the results are divided into quantitative and qualitative findings.

\subsection{Demographic and Employment Characterization}

The demographic and employment characteristics of the participants are detailed in Tables 1 and 2, respectively.

In terms of caring responsibility, almost half (44\%) of the participants reported having to provide care, with most reporting caring for children (26\% pre-school age, 33\% primary school age, $31 \%$ secondary school age), while $26 \%$ stated they cared for other dependent family members and $8 \%$ cared for someone else. Data from these 39 individuals exceeds $100 \%$, indicating that in some cases, people had caring responsibilities to more than one person. The amount of time spent engaged in caring responsibilities in a typical day ranged from up to $1 \mathrm{~h}$ to more than $12 \mathrm{~h}$ with the most commonly reported duration $3-4 \mathrm{~h}$ $(22.5 \%)$, followed by $1-2 \mathrm{~h}(17.5 \%)$ or more than $12 \mathrm{~h}(17.5 \%)$. All of those with caring responsibilities reported that these increased due to the pandemic. More than a quarter of staff members with caring responsibilities (30\%) indicated that this increase impacted their work negatively. There was no association between caring responsibility and gender $\left(\chi^{2}(1)=0.95, p=0.378\right)$, ethnicity $\left(\chi^{2}(2)=1.79, p=0.408\right)$ or disability $\left(\chi^{2}(1)=0.26\right.$, $p=0.611)$. However, there was an associated between caring and age $\left(\chi^{2}(3)=20.06\right.$, 
$p<0.001$ ). Younger ( $26-35$ years) and older (56-70 years) group individuals were less likely to have caring responsibilities whereas this was more common in $36-45$ years and $46-56$ years of age.

The mean social identity score of 53.51 (SD = 10.81) indicated that being an academic at the university was a moderately strong factor in their social identity. This did not differ significantly between any of the different employment groups: full vs. part time; fixed term vs. open-ended (noting casual employment status was excluded from analysis due to low sample size); seniority; teaching level and faculty. Furthermore, social identity scores were not significantly different between genders, age groups, ethnic groups, disability status, or caring role.

\subsection{Technology and Digital Capabilities}

Prior to the lockdown, most teaching staff $(81 \%)$ had access to university PCs or laptops. Following the lockdown and closure of university's campuses, only half (48\%) of academics stated that the university provided them with the necessary equipment to continue their work from home. While access to generic software remained largely unchanged, there was a $32 \%$ decrease in the number of respondents with access to specialist research software. Most academics had adequate equipment $(56 \%)$ and space $(78 \%)$ to work from but almost half $(48 \%)$ encountered additional financial costs to achieve this. Figure 1 shows a breakdown of academics' digital abilities and digital confidence as percentages. The overall ability score was $50 \%$ and the overall confidence score was $57 \%$. This indicates that digital confidence was almost on par with the actual digital skills.

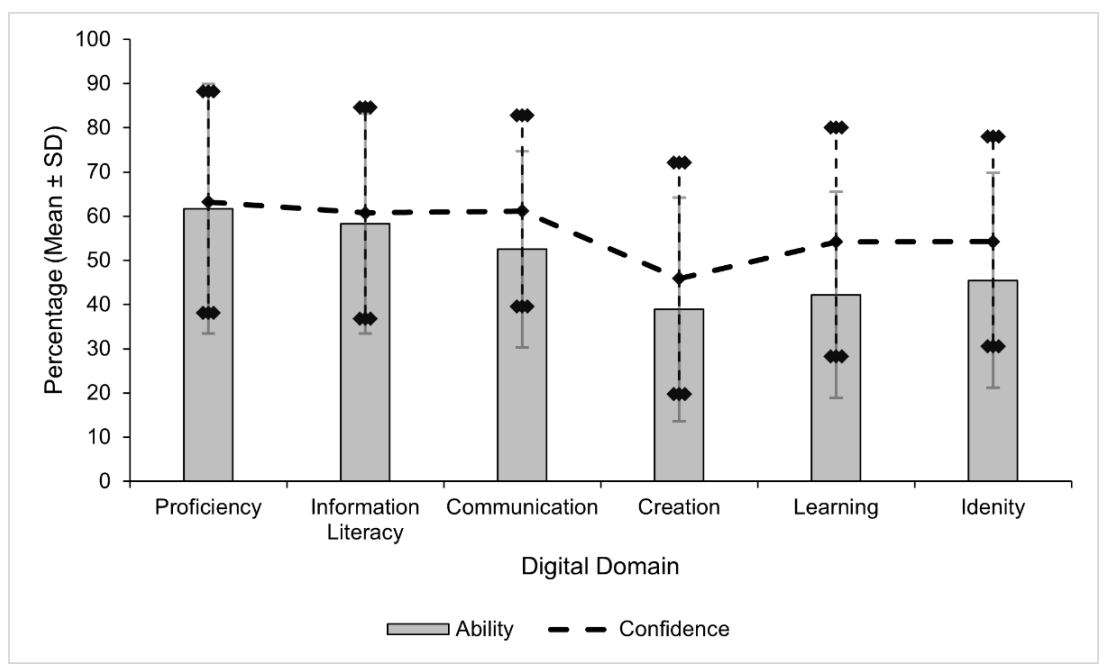

Figure 1. Academics' digital abilities and digital confidence. Error bars represent the standard deviation of the measure (grey line $=$ ability; black diamond $=$ confidence).

Given the importance of digital capabilities in designing and delivering online education we examined whether overall digital confidence and ability were predicted by demographic and employment factors. As summarized in Table 3, regression analysis reveals several significant predictors of digital confidence. Firstly, older age groups had less digital confidence. Secondly, full time staff are more confident than part time staff. Staff within the natural and mathematical science faculty also had greater confidence. Finally, greater social identity as an academic was associated with greater confidence. For digital ability, age, faculty, and social identity predictions remain significant.

\subsection{Online Education Experiences and Workload}

Most staff reported using synchronous online activities to replace face-to-face teaching (85\%), shifting to online video calling platforms. Many also used asynchronous online activities $(71 \%)$, such as lecture capture. For assessment, the most frequent alternative was 
written coursework (76\%), followed by online exams (69\%). Time dedicated to teaching changed during the pandemic; prior to COVID-19, the most reported duration spent teaching was $21-40 \%$ of their time (31\%), followed by $41-60 \%(23 \%)$. However, during the pandemic the mode response was over $80 \%$ of their time (27\%), followed by $61-80 \%(24 \%)$. Despite this, $47.5 \%$ did not report a change in the amount of teaching, and a further $20.0 \%$ reported a decrease in teaching. The remaining 32.5\% reported an increase, demonstrating that increased workload was not equally distributed across staff. Workload change was calculated by subtracting post-COVID workload level from pre-COVID workload, such that a positive value indicates a decrease in workload during COVID. As summarized in Table 4, the only significant predictor of workload changes was academic role or seniority, such that more senior staff had greater increases in workload, although the overall regression model was non-significant.

Table 4. Regression coefficients for predicting pandemic induced workload-changes.

\begin{tabular}{|c|c|c|c|c|}
\hline \multirow[t]{2}{*}{ IVs } & \multicolumn{4}{|c|}{ Workload Changes } \\
\hline & $\mathbf{b}$ & & & Sig \\
\hline Gender & -0.03 & -0.94 & 0.89 & 0.951 \\
\hline White non-British ${ }^{1}$ & -0.54 & -1.36 & 0.28 & 0.194 \\
\hline BAME $^{1}$ & -0.37 & -1.38 & 0.65 & 0.470 \\
\hline Age & 0.11 & -0.29 & 0.51 & 0.580 \\
\hline Disability & 0.17 & -0.70 & 1.04 & 0.696 \\
\hline Caring & -0.30 & -1.05 & 0.45 & 0.420 \\
\hline Status & -0.03 & -0.98 & 0.93 & 0.953 \\
\hline Contract type & -0.11 & -0.98 & 0.76 & 0.800 \\
\hline Seniority & -0.40 & -0.72 & -0.07 & $<0.05$ \\
\hline Teaching level & -0.32 & -1.05 & 0.42 & 0.392 \\
\hline Arts/Humanities ${ }^{2}$ & 0.28 & -1.10 & 1.65 & 0.685 \\
\hline Social Sci.\&Econ. ${ }^{2}$ & 0.27 & -0.61 & 1.14 & 0.543 \\
\hline Natural/Maths Sci. 2 & -0.74 & -2.00 & 0.51 & 0.240 \\
\hline Social identity & -0.00 & -0.04 & 0.03 & 0.819 \\
\hline Safe space to work & -0.07 & -1.00 & 0.85 & 0.870 \\
\hline Equipped space & -0.23 & -1.09 & 0.62 & 0.587 \\
\hline Digital abilities & -0.00 & -0.03 & 0.03 & 0.930 \\
\hline Digital confidence & -0.00 & -0.03 & 0.03 & 0.922 \\
\hline
\end{tabular}

Model: $\mathrm{R} 2=0.36, \mathrm{~F}(18,45)=1.41, p=0.173 .{ }^{1}$ Reference value, White British $;{ }^{2}$ Reference value, Medical Sciences.

\subsection{Predicting Mental Wellbeing}

Respondents had relatively low levels of mental wellbeing; mean SWEMWBS score was 20.10 ( $\mathrm{SD}=3.19)$. This is $3.5,95 \% \mathrm{CI}(2.69,4.33)$, points below the normative measure for the general population pre-COVID [31]. As summarized in Table 5, the factors predicting mental wellbeing were assessed in a multiple regression analysis. Although the overall model was significant, no single predictor reached significance, although there was a trend towards this for social identity.

Table 5. Regression coefficients for mental wellbeing.

\begin{tabular}{ccccc}
\hline IVs & \multicolumn{4}{c}{ Mental Wellbeing } \\
\hline & b & \multicolumn{2}{c}{$\mathbf{9 5 \%}$ CI } & Sig \\
\hline Social Identity & 0.07 & -0.00 & 0.14 & 0.064 \\
Workload change & 0.28 & -0.31 & 0.87 & 0.344 \\
Digital ability & 0.01 & -0.05 & 0.08 & 0.700 \\
Digital capability & 0.03 & -0.04 & 0.09 & 0.410 \\
\hline
\end{tabular}

Model: $\mathrm{R} 2=0.16, \mathrm{~F}(4,71)=3.286, p=0.016$. 


\subsection{Qualitative Themes}

Four themes and subthemes were identified which are elaborated below: remote working, transition to online teaching, experiences of online assessment, and technological support and challenge.

\subsubsection{Remote Working}

Six sub-themes were identified under the remote working theme: home office, distractions, work-life balance, motivation, monotony, and university support.

Home office: In terms of space to work at home, responses indicated staff were working in a range of spaces. For example, some academics reported having their own private workspace at home: "I am lucky enough to have a fairly big home, where I can have my own study, [and] where my partner can have her own study" (Interview 9). Others reported having sub-optimal workspace: "I live in a flat share, and the only place I can really work is my bedroom. So I'm spending a lot of time in that space" (Interview 4).

A minority of respondents felt home-working was an improvement, with better scenery and access to natural light. Some respondents identified no change in their work environment or reflected that the changes had no impact on their ability to work. However, many identified problems related to the accessibility of resources and the ergonomics of home-working. Staff identified problems including not have fully functioning laptops, headphones, or printers at home. While a minority of these concerns were alleviated by university provided resources, most respondents were left to resolve these issues themselves, privately purchasing new equipment. Many were working in non-ergonomic spaces: "I don't have a very good desk setup in terms of ergonomics" (Interview 7).

Distractions: Although most respondents had a quiet place to study at home, distraction was something they talked about. For some distractions increased; parental responsibilities impacted the work of some academics: "You can't be working full time and doing childcare. And you had a lockdown, the main issue was the closing down of child minders, nursery schools and so on. So that was the main factor" (Interview 12). Others mentioned that remote working involved fewer distractions compared to the alternative, which for some meant shared offices: "I think the silence has been helpful in that before I was working in a shared office space. So there was a lot of noise all the time, which was obviously quite distracting" (Interview 4).

Work-life balance: Most respondents experienced some changes in how they managed their personal and work lives due to the pandemic. Some academics were able to spend more time with their partners or families, for example, due to the absence of time spent commuting: "I feel like I have a lot more free time without commuting, which is so nice, you know, like being able to be in my workspace immediately, I feel like in some ways, my quality of life has improved because of that, because at the end of the day, at five o'clock, I can switch off my computer, and I'm home and I can already do the things that I want to spend my free time doing rather than sitting on the tube" (Interview 1). Others had difficulties in separating work and home responsibilities when they happened within the same space. Parents were forced to balance full-time work and caring responsibilities, leading some to work unsociable hours. A minority said that they had fewer meetings. The combination of having more time and fewer meetings led to more flexibility around starting times and breaks, and for some, this increased productivity.

Motivation: Motivation fluctuated for most respondents. Some felt demotivated in the absence of varied activities and time off: "I think at the beginning, I was feeling extremely motivated and productive. And I did lots of different additional projects. And then I feel that I had a little bit of a low. And maybe, I think, mainly because I haven't actually taken any proper holiday" (Interview 4). Motivation levels were also affected by teaching, which some described as impersonal and distant. However, a minority felt more motivated to be productive: "I've actually found probably being more productive or able to get through more" (Interview 6). This increased productivity related to ease of 
access to teaching materials from home, reduced distractions, and the ease of getting hold of colleagues via online video calling platforms.

Monotony: The monotony of remote working and restrictions was mentioned by some respondents. Monotony and the lack of recreational activities outside work were identified as deterrents to good mental health: "It's not that I don't [ ... ] enjoy myself being at home or relaxing with my partner or with my friends. We are locked down. I've been restricted at home, so it's not a direct effect of not being able to work [on] campus, but it's a general effect of the situation. I mean, at this point, I'm not even enjoying the walks in the park. I just got sick of it because there are no alternatives, [ ... ] so I can't be much more positive about that, even though I would love to" (Interview 2). The absence of casual interactions at work was also a factor that used to break up the workday in the office. Some academics arranged meetings that were not related to work to facilitate casual interactions.

University Support: Support consisted of efficient communication, acknowledgement, and regular drop-in sessions where they could share their worries and receive support from others. Most respondents felt adequately supported by their immediate department and the university, which helped them navigate the abrupt changes: "I felt very well supported all across. And I think that helped me a lot, trying to manage the stress and the change" (Interview 5). However, several academics mentioned that communication from the leadership could have been improved, while some were not included in some decisions which directly involved them, such as assessment arrangements. One academic mentioned that junior staff could be better supported: "as a more junior member of staff, I feel like that could have been greater as support in places. Even just kind of checking in to see if you're okay, and like just, you know, how your workload is, etc. And I don't feel there's been a huge amount of that" (Interview 4). Administrative support was also mentioned, with one interviewee pointing towards the lack of administrative support, a deficiency described as "really stressful. Deadlines are approaching and nobody comes back to you, HR doesn't work, library services don't work" (Interview 5).

Parents and carers felt acknowledged by the university and were encouraged to take a flexible approach in balancing caring responsibilities and full-time work. Despite this support, some noted that their workloads remained difficult to manage and that work had to be completed regardless. One interviewee managed this by working unsociable hours to balance home responsibilities and work: "especially at the beginning, I don't remember having weekends at all, there was not a chance [... I I had maybe six hours a day and then I had to work it out in the weekends just to make it up" (Interview 5).

Some respondents mentioned the importance of informal support, such as coffee mornings, in reducing loneliness, conserving normalcy, and mimicking the pre-pandemic interactions. Academics also mentioned that the newness of the situation facilitated interaction between colleagues, either by helping or receiving digital help from others.

\subsubsection{Transition to Online Teaching}

Two sub-themes were identified: redesigning teaching materials and interactions with students.

Redesigning teaching materials: Academics noted that creating materials for online teaching involved a lot of work: "A module that is prepared to be taught fully online is very different from the online version of a module that is meant to be face-to-face. Now what $\mathrm{I}$ 'm saying is fairly trivial and may appear obvious, but there is a fundamental difference because the way you prepare the material before and for a fully online module" (Interview 9). This increased work, left academics feeling overwhelmed: "There's been a massive increase in workload. So I feel like I'm working at, you know, $150 \%$. But there's still just an endless to do list" (Interview 4). The switch to online education also meant staff spent time engaging in digital skills training or supporting colleagues to develop these skills, including the ability to use video calling platforms (e.g., Microsoft Teams) for setting up and attending meetings and recording software (e.g., Kaltura) to create teaching materials. Despite the workload and need to upskill, some positive aspects were reported, including 
the opportunity to improve teaching materials and work collaboratively with colleagues towards a common goal.

Interactions with students: Experiences around student engagement varied. Some reported decreased student attendance and participation and limited feedback on online teaching: "it was quite hard not being able to see the students because most, I think everybody had their camera off. You can't hear them, because the microphones are also off. So, you know, it's like talking into it into the void. You don't know if anybody's there" (Interview 10). Some respondents felt frustrated about the lack of information they had about assessments at the beginning of the pandemic, as they could not answer students' questions. Nonetheless, some respondents reported increased interactions and remarked that students quickly adapted to online teaching: "it feels a lot more settled now in terms of just being able to deliver the classes and know that my students are going to be there on the other side of the screen, and I'm not just going to be talking to 20 little black boxes" (Interview 1).

\subsubsection{Experiences of Online Assessment}

Three sub-themes were identified: marking and feedback, integrity, and assessment guidelines.

Marking and feedback: The use of online assessment where previous forms were on paper or in person received mixed support from staff. Most respondents found online marking to be more efficient because it was easier to read: "I think it'd be nice to keep doing online assessment, [ . . ] I think it does work better, [ . . ] you don't have to worry about students' handwriting or that you've missed a page that a student's written on" (Interview 11). However, others felt that it was more time-consuming because students expected more thorough feedback. Additionally, use of some online tools such as audio feedback created difficulties: "I find it laborious; I find it far harder to mark exam scripts, and far harder to mark coursework than having a printed version" (Interview 8). One interviewee noted that online marking worked particularly well for online presentations, due to higher attendance from members of the teaching team and greater level of feedback: "if we're doing student presentations, and you can get seven other academics in the call with you, you've got a much better chance of getting a much better assessment. So it's been really nice to have more colleagues involved in those assessments. Normally, it's just two of us in a room with students, it's been lovely to have more colleagues" (Interview 8).

Integrity of assessment: Most respondents raised concerns about the integrity of online assessments, which they felt was compromised. These concerns were particularly notable for STEM subjects where limited correct answers would make it harder to identify any collusion or other forms of cheating: "in maths, physics, chemistry, and some extent in computer science, where the answers are just facts. Two correct answers will look very much the same" (Interview 10). Despite this, most agreed that this related to the time available to prepare the online assessment rather than an issue intrinsic to this form of assessment.

Assessment guidelines: Most respondents noted a lack of clear and consistent guidelines around assessment. Constant changes regarding assessment, marking and feedback were mentioned. Due to these changes, academics often doubted whether the received information was definitive: "just get the record straight, come back to me with just one final answer. And then I'll just generate the material as you request it" (Interview 5). This put academics in a difficult position as students were demanding clarifications. Nonetheless, a minority of academics noted that their departments gave clear guidelines and thus adjusted to the transition to online learning quickly.

\subsubsection{Technological Support and Challenges}

Three sub-themes were identified under technical support and challenges: access and connectivity, digital training and support, and digital working.

Access and connectivity: Academics questioned whether they had adequate provision of hardware and software. Two interviewees said that they have had to work with what they had, while one mentioned that they had been offered a tablet. Several academics 
mentioned that they had incurred additional financial costs to equip their home offices. These costs ranged from office equipment to more costly recording equipment meant to enhance the quality of teaching materials: "It's been a considerable financial investment for me. I've, you know, bought desks and chairs and new speaker systems and a new monitor and microphones and all that kind of stuff" (Interview 8). Many also experienced internet connection problems, particularly in instances where they shared the internet with household members. Several academics noted that they incurred additional costs for upgrading their home broadband and one academic affirmed that the university's "reliance on home broadband for teaching is going to be really a very weak point" (Interview 10).

Digital training and support: While digital training and support were provided, the timing, format and content of the training materials could have been improved. Academics stated a preference for simple training and technology. This did not align with the experience of all; "I feel] slightly overwhelmed with the amount of different software and technology that we're told about. So it's just difficult to have the time to ... get into it and learn about it." (Interview 4). One solution to the information overload was to create training materials that are short and easy to access: "And then up to the point that in one of the meetings, I told them, I feel overwhelmed by the amount of information. Can we distil it into, you know, a couple of one pagers that people can use [ ... ].These one pagers are fantastic because you know, even if you have not engaged so far as an academic or as a professional services, [ ... ], you can just download this one pager and there is there are instructions on what you should be doing" (Interview 9). Despite the high volume of information, a few respondents believed that digital support was basic and advocated for more detailed training sessions.

Several academics noted their digital training was partly provided by their tech-savvy colleagues. One respondent believed they were "better than the ones that are on the official university sites" (Interview 6). One academic involved in creating the extra digital content admitted that they "personally really enjoy and thrive on giving support to my colleagues" and that once the pandemic hit, they "started producing a whole load of tutorial videos for my colleagues to help them teach online. So I've produced about 60 videos, which are all up on YouTube and the college stream site where people can drop in and learn how to set up a meeting in teams or learn how to deliver a lecture online, learn how to record a PowerPoint presentation, learn how to edit and do all this other stuff. So for me, it's been very positive in that I've had the opportunity now to really show what we can do as staff to support each other and showcase what we're capable of as a staff, which has been brilliant. You know, it's nice to have that opportunity to do something positive for the community as well as my own career" (Interview 8). Nonetheless, these materials were added to the usual workload and the academics involved did not receive any additional pay. In fact, one interviewee pointed out: "I see lots of people's digital efforts, and none of it was gonna be paid extra and stuff. A lot of it's just kind of good citizen type behaviour" (Interview 12).

Several academics highlighted the need for far bigger technological changes, such as rethinking the university's IT infrastructure to optimize it for online teaching and assessment. One academic highlighted the need to consult experts in online security in the context on delivering online education

Digital working: Academics identified both advantages and disadvantages to working online. Online meetings between academics increased flexibility, were time-effective and increased attendance to research meetings, contributing positively to learning and development. Several academics considered that online hosted meetings and conferences can widen participation and improve access. Many said they would like to continue meeting online even when face-to-face teaching resumes: "I definitely hadn't used [Microsoft] Teams before, and things like that. [ ... ] And it was actually really useful. I think, even going forward, if we were, you know, to return to do things the way we did before, I think those are things that I will carry on using" (Interview 11). However, for some, the frequency of online meetings was burdensome. One interviewee said there was an "overabundance of online meetings, probably to compensate for the fact we are not able to meet face-to-face anymore [ ... ] which meant that there was very little time to do anything else but participate in the meetings" (Interview 9). 


\section{Discussion}

The pandemic affected academics on multiple fronts. On a practical level, most academics had a space to work from at home, although this was not always optimal and some incurred additional costs, including paying for internet upgrades, and equipment for teaching. Remote working was also associated with difficulties in work-life balance and distractions for some. Almost half of the academics surveyed had caring responsibilities and all reported that these had increased during the pandemic. A quarter indicated this increase had impacted negatively on their work. Qualitative data indicates that this was in part due to the difficulty juggling childcare and work and the interruptions to work that result from this. Interestingly, despite previous work indicating that females are more likely to have caring responsibilities [32], our data did not support this. We did however, find that those in middle age were most likely to be caring, in line with previous research [33].

As well as switching to remote working, the pandemic required a rapid switch to online education delivery, including assessment. Anecdotal evidence suggested this resulted in significant increases in workload for academics. Our data support this to some extent, in that around 30\% reported an increase in their teaching workload, in contrast to around $50 \%$ having the same teaching load and the remainder seeing a decrease. The only factor that predicted increased workload was seniority. The senior academics who saw an increase in their workload were also likely to be spending substantive amounts of time in meetings, developing plans to manage the impact of the pandemic, making this group arguably most vulnerable to burnout, which is thought to have been widespread in academia during the pandemic [34]. Increased teaching time for senior academics is also likely to have knock-on effects elsewhere. For example, interviews highlighted that junior staff felt a lack of acknowledgement and support, which would typically come from more senior staff. Not surprisingly, many academics interviewed reported working longer hours and some highlighted that the excessive teaching workload prevented them taking time off, especially in cases where they were also juggling caring responsibilities. Furthermore, although most found the university supportive and were able to work flexibly, the work still needed to be done by them, meaning the benefits of support were limited. The dominance of teaching reported here, aligns with data from a report conducted in May and October 2020 in a sample of over 1000 academics from Europe, Asia and the Americas, which found that 53\% of their sample were busier in October 2020 compared to before the pandemic and $48 \%$ of those involved in primary research were producing fewer outputs [35], suggesting an increase in non-research related activities.

The switch to online education, despite its associated workload, was viewed positively by some as an opportunity to work in teams and improve on previous teaching, although there was a sense of frustration about initial interactions with students. More concern was raised about assessment. This included meeting the expectations of students, a point previously noted in the literature [36]. The issue of ensuring integrity in assessment was also raised when assessments moved online. This has been identified prior to the pandemic for online courses and evidence suggests that, contrary to popular opinion, cheating is no more prevalent online than it is in other formats [37]. Nonetheless, staff in the present study noted that these concerns related to expectations and timescales which could be addressed in a non-emergency situation.

Both the transition to online education and remote working are likely to rely on digital abilities and confidence. Our data indicate that older age groups were less able and confident with digital skills. Previous research has indicated that older adults are less digitally-able than their younger counterparts and it has been noted that support for developing skills in these individuals may require a bespoke approach [38]. For example, older adults may benefit from a mentoring-style approach and support between any synchronous sessions [38]. We also found that those in natural and mathematical sciences were more able and confident than other faculties. A stronger social identity as an academic was associated with stronger ability and greater confidence. Employment status also predicted confidence with full time staff more confident than part time staff. Killen 
(2020) [14] reported that most academics, while eager to develop their digital skills, do not have the time required to do so. Time constraints may explain some of the findings here. For example, part time staff and those in more junior positions, irrespective of age, might be more likely to be overburdened with other tasks such as pastoral care and administrative tasks. These factors need further consideration in future research. The relationship with social identity is harder to interpret. It is possible that a stronger social identity could have arisen due to better skills in this area or due to participation in more training. Qualitative data did not contribute any further information here, and therefore, this is an area that warrants further investigation in future.

Despite increasingly high expectations of academics [19], the mental wellbeing of this group has received relatively little attention. Prior to the pandemic, Kinman and Johnson (2019) [39] noted that academics were having to fulfil numerous additional roles at the same time as role clarity, autonomy and collegiality were declining, contributing to an increased volume and intensity of work. Reports had also shown high levels of burnout and mental disorders [11,12]. The pandemic has accentuated these concerns. Given the increased workload, reliance on digital skills, and the possible changes to social identity due to the different work activities, we expected that these factors may predict mental wellbeing. Overall, our findings support low levels of wellbeing, but this was not predicted by the hypothesized factors in our quantitative analysis. Our data revealed a trend towards significance for stronger social identity being associated with better mental wellbeing only.

The interview data does, however, strengthen this finding in that academics admitted that supportive departments and colleagues helped them navigate the abrupt transition to online education. Furthermore, many mentioned that the pandemic created a strong sense of collegiality and team spirit which acted as motivators and likely contributed positively to social identity as an academic and wellbeing. Encouragingly, most respondents agreed that they received adequate support throughout the pandemic, which might have had similar effects. Despite those positives, the relationship between academics and the university changed during the pandemic. This is not surprising considering that work shifted from the office to the home environment and that interactions with colleagues and students had to be moved online. In fact, the majority mentioned that they longed for casual interactions with colleagues and that some activities were more difficult to fulfil from home. Furthermore, the strained relationship between academics and the university is likely to impact on academic roles and the academic identity, which could then impact wellbeing. Nonetheless, the interviews helped identify some benefits of working from home; namely, many respondents believed that online meetings increased access to research meetings and conferences. These findings suggest that mental wellbeing in academia is likely multifactorial; while strong social identity as an academic may be a protective factor, being away from campus and colleagues can impact the manner in which academics perceive their relationship with the university.

This work has several strengths. First, we present quantitative and qualitative data from academics specializing in various fields, who routinely engage in teaching and whose activities were inevitably impacted by the abrupt transition to online education in Spring 2020. Second, data was captured at two key time points: quantitative data was collected in May-June 2020 when academics had experienced the emergency transition to online education, but uncertainty around the provision of teaching and assessment remained, whilst interviews were conducted in August-September 2020 when academics had more clarity regarding the approach that is required for distance learning. Nonetheless, our findings must be considered carefully in light of several limitations. First, the sample size is relatively small and there are concerns that the most burdened academics were the ones least likely to take part due to limited time and resources. While data collection was specifically planned to capture critical moments in the university, it is likely that these periods affected the academics' availability to engage in voluntary activities such as research. Second, in relation to the university staff population in the UK, our survey sample overrepresented women and younger academics, and under-represented individuals from 
a BAME background [40]. Third, the timings of the online survey and subsequent interviews merely captured a snapshot of the academics' experience as the pandemic brought numerous dynamic changes that influenced their workloads and livelihoods. Lastly, we present data from a large London-based university that arguably had sufficient financial resources to provide digital skills training and equipment for its staff and that had a minimal technological infrastructure that served as a foundation for the provision of online education at the start of the pandemic. We recognize that these aspects can vary between universities and countries.

In summary, this mixed-methods study investigated the transition to online education during two key stages in the COVID-19 pandemic for the Higher Education sector. By showing that poorer digital abilities were more prevalent in older staff and those who are part-time lack digital confidence, we recommend that universities tailor their programs to support these groups. Many UK universities, including our own, offered rapid, just-in-time, training to staff during the pandemic which could be accessed online both synchronously and asynchronously. The rapidity with which the training was made available meant that it was not possible to tailor all training to specific groups who may need greater or different support. As we move beyond the pandemic there is an opportunity to build on this by offering more personalized training to support the needs of all staff. Increased teaching time and high workloads are two concerning findings of the current work. With the strong focus in recent years on improving the mental health of students, it is worrying that the wellbeing of academics, who are often the first point of contact and have pastoral duties, is neglected and even pushed to the limit during an international health emergency. On the positive note, this work shows that strong academic identity is associated with better digital abilities and confidence and may be a protective factor for mental wellbeing and that online meetings can facilitate communication and collaboration between colleagues, as well as widening participation in research activities. Many academics enjoyed working from home outside of the initial crisis and there were reports of increased productivity and time for activities outside academia. We therefore recommend that the Higher Education sector rethinks some of its structures before returning to the pre-pandemic conditions. Furthermore, the University Mental Health Charter [41] published in 2019 includes provision for staff mental health and wellbeing, suggesting that the sector is now primed to seriously consider staff and students. More recently in 2021, a Charter Award system has been introduced which will allow university to apply for the Charter Award by demonstrating they meet certain criteria. The findings presented here suggest areas which universities might focus on to improve wellbeing as part of this process.

Author Contributions: Conceptualization, E.J.D., N.C.B., J.L.H.F., S.E.; Data collection, L.M.D., A.B.; Data Analysis L.M.D., A.B., J.L.H.F., N.C.B., K.J.M., E.J.D.; Writing—review and editing, L.M.D., K.J.M., E.J.D. All authors have read and agreed to the published version of the manuscript.

Funding: This research was funded by an internal Institutional Grant to E.J.D., N.C.B., J.L.H.F., S.E.

Institutional Review Board Statement: The study was conducted according to the guidelines of the Declaration of Helsinki, and approved by the Institutional Review Board (or Ethics Committee) of King's College London (protocol code MRA-19/20-18209 and 26 March 2020).

Informed Consent Statement: Informed consent was obtained from all subjects involved in the study.

Data Availability Statement: Data is available on reasonable request from the corresponding author.

Conflicts of Interest: The authors declare no conflict of interest.

\section{References}

1. Malisch, J.L.; Harris, B.N.; Sherrer, S.M.; Lewis, K.A.; Shepherd, S.L.; McCarthy, P.C.; Spott, J.L.; Karam, E.P.; Moustaid-Moussa, N.; Calarco, J.M.; et al. Opinion: In the wake of covid-19, academia needs new solutions to ensure gender equity. Proc. Natl. Acad. Sci. USA 2020, 117, 15378-15381. [CrossRef] [PubMed]

2. Aucejo, E.M.; French, J.; Ugalde Araya, M.P.; Zafar, B. The impact of covid-19 on student experiences and expectations: Evidence from a survey. J. Public Econ. 2020, 191, 104271. [CrossRef] [PubMed] 
3. Bourion-Bédès, S.; Tarquinio, C.; Batt, M.; Tarquinio, P.; Lebreuilly, R.; Sorsana, C.; Legrand, K.; Rousseau, H.; Baumann, C. Psychological impact of the covid-19 outbreak on students in a french region severely affected by the disease: Results of the pims-cov 19 study. Psychiatry Res. 2021, 295, 113559. [CrossRef] [PubMed]

4. Cao, W.; Fang, Z.; Hou, G.; Han, M.; Xu, X.; Dong, J.; Zheng, J. The psychological impact of the covid-19 epidemic on college students in china. Psychiatry Res. 2020, 287, 112934. [CrossRef] [PubMed]

5. Rainbow, S.; Dorji, T. Impact of covid-19 on medical students in the united kingdom. Germs 2020, 10, 240-243. [CrossRef]

6. Singh, S.; Roy, D.; Sinha, K.; Parveen, S.; Sharma, G.; Joshi, G. Impact of covid-19 and lockdown on mental health of children and adolescents: A narrative review with recommendations. Psychiatry Res 2020, 293, 113429. [CrossRef] [PubMed]

7. Torun, F.; Torun, S.D. The psychological impact of the covid-19 pandemic on medical students in turkey. Pak. J. Med. Sci. Q. 2020, 36, 1355-1359. [CrossRef]

8. Changwon, S.; Hegde, S.; Smith, A.; Wang, X.; Sasangohar, F. Effects of covid-19 on college students' mental health in the united states: Interview survey study. J. Med. Internet Res. 2020, 22, e21279.

9. Al-Taweel, D.; Al-Haqan, A.; Bajis, D.; Al-Bader, J.; Al-Taweel, A.M.; Al-Awadhi, A.; Al-Awadhi, F. Multidisciplinary academic perspectives during the covid-19 pandemic. Int. J. Health Plann. Manag. 2020, 35, 1295-1301. [CrossRef]

10. Watermeyer, R.; Crick, T.; Knight, C.; Goodall, J. Covid-19 and digital disruption in uk universities: Afflictions and affordances of emergency online migration. High. Educ. 2021, 81, 623-641. [CrossRef]

11. Watts, J.; Robertson, N. Burnout in university teaching staff: A systematic literature review. Educ. Res. 2011, 53, 33-50. [CrossRef]

12. Gorczynski, P.; Hill, D.; Rathod, S. Examining the construct validity of the transtheoretical model to structure workplace physical activity interventions to improve mental health in academic staff. Community Med. 2017, 1, 002.

13. Rapanta, C.; Botturi, L.; Goodyear, P.; Guàrdia, L.; Koole, M. Online university teaching during and after the covid-19 crisis: Refocusing teacher presence and learning activity. Postdigit. Sci. Educ. 2020, 2, 923-945. [CrossRef]

14. Killen, C.; Langer-Crame, M. Teaching Staff Digital Experience Insights Survey 2020: UK Higher Education Findings. Available online: https:/ / www.jisc.ac.uk/reports/teaching-staff-digital-experience-insights-survey-2020-uk-higher-education (accessed on 1 October 2021).

15. Katz, V.S.; Jordan, A.B.; Ognyanova, K. Digital inequality, faculty communication, and remote learning experiences during the covid-19 pandemic: A survey of u.S. Undergraduates. PLoS ONE 2021, 16, e0246641. [CrossRef] [PubMed]

16. Hughes, G.; Panjawni, M.; Tulcidas, P.; Byrom, N. Student Mental Health: The Role and Experiences of Academics. Available online: https: / / derby.openrepository.com/handle/10545/622114 (accessed on 1 October 2021).

17. McAllister, M.; Wynaden, D.; Happell, B.; Flynn, T.; Walters, V.; Duggan, R.; Byrne, L.; Heslop, K.; Gaskin, C. Staff experiences of providing support to students who are managing mental health challenges: A qualitative study from two australian universities. Adv. Ment. Health 2014, 12, 192-201. [CrossRef]

18. Hughes, G.J.; Byrom, N.C. Managing student mental health: The challenges faced by academics on professional healthcare courses. J. Adv. Nurs. 2019, 75, 1539-1548. [CrossRef]

19. Urbina-Garcia, A. What do we know about university academics' mental health? A systematic literature review. Stress Health 2020, 36, 563-585. [CrossRef]

20. Cadez, S.; Dimovski, V.; Groff, M.Z. Research, teaching and performance evaluation in academia: The salience of quality. Stud. High. Educ. 2017, 42, 1455-1473. [CrossRef]

21. Guarino, C.M.; Borden, V.M.H. Faculty service loads and gender: Are women taking care of the academic family? Res. High. Educ. 2017, 58, 672-694. [CrossRef]

22. Bentley, S.V.; Peters, K.; Haslam, S.A.; Greenaway, K.H. Construction at work: Multiple identities scaffold professional identity development in academia. Front. Psychol. 2019, 10, 628. [CrossRef]

23. Daniel, B.K. Contestable professional academic identity of those who teach research methodology. Int. J. Res. Method Educ. 2018, 41, 548-561. [CrossRef]

24. Dery, K.; Hafermalz, E. Seeing is belonging: Remote working, identity and staying connected. In The Impact of Ict on Work; Springer: Singapore, 2016; pp. 109-126. [CrossRef]

25. Ysseldyk, R.; Greenaway, K.H.; Hassinger, E.; Zutrauen, S.; Lintz, J.; Bhatia, M.P.; Frye, M.; Starkenburg, E.; Tai, V. A leak in the academic pipeline: Identity and health among postdoctoral women. Front. Psychol. 2019, 10, 1297. [CrossRef] [PubMed]

26. Haslam, S.A.; Jetten, J.; Postmes, T.; Haslam, C. Social identity, health and well-being: An emerging agenda for applied psychology. App. Psych. 2008, 58, 1-23. [CrossRef]

27. Morris, C. "Peering through the window looking in": Postgraduate experiences of non-belonging and belonging in relation to mental health and wellbeing. Stud. Grad. Postdr. Educ. 2021, 12, 131-144. [CrossRef]

28. Cameron, J.E. A three-factor model of social identity. Self Identity 2004, 3, 239-262. [CrossRef]

29. Braun, V.; Clarke, V. Using thematic analysis in psychology. Qual. Res. Psychol. 2006, 3, 77-101. [CrossRef]

30. Braun, V.; Clarke, V. Reflecting on reflexive thematic analysis. Qual. Res. Sport Exerc. Health 2019, 11, 589-597. [CrossRef]

31. Warwick Medical School. Collect, Score, Analyse and Interpret Wemwbs. Available online: https://warwick.ac.uk/fac/sci/med/ research/platform/wemwbs/using/howto/ (accessed on 1 October 2021).

32. Manzo, L.K.C.; Minello, A. Mothers, childcare duties, and remote working under covid-19 lockdown in italy: Cultivating communities of care. Dialogues Hum. Geogr. 2020, 10, 120-123. [CrossRef] 
33. Dahlberg, L.; Demack, S.; Bambra, C. Age and gender of informal carers: A population-based study in the uk. Health. Soc. Care Community 2007, 15, 439-445. [CrossRef] [PubMed]

34. Gewin, V. Pandemic Burnout Is Rampant in Academia; Nature Publishing Group. Available online: https://media.nature.com/ original/magazine-assets/d41586-021-00663-2/d41586-021-00663-2.pdf (accessed on 1 October 2021).

35. Watchorn, D.; Heckendorf, E.; Smith, C. Locked down, Burned out. Publishing in a Pandemic: The Impact of Covid on Academic Authors; Germany. Available online: https://blog.degruyter.com/wp-content/uploads/2020/12/Locked-Down-Burned-OutPublishing-in-a-pandemic_Dec-2020.pdf (accessed on 1 October 2021).

36. Hepplestone, S.; Mather, R. 'Meeting Rising Student Expectations of Online Assignment Submission and Online Feedback'. [Online]. In Proceedings of the 11th International Computer-Assisted Assessment Conference, Learning and Teaching Development, Loughborough University, Loughborough, UK, 10-11 July 2007. Available online: http:/ / www.caaconference.co. uk/pastConferences / 2007/proceedings/Hepplestone\%20S\%20Mather\%20R\%20n1_formatted.pdfHepplestone (accessed on 2 January 2021).

37. Harris, L.; Harrison, D.; McNally, D.; Ford, C. Academic integrity in an online culture: Do mccabe's findings hold true for online, adult learners? J. Acad. Ethics 2020, 18, 419-434. [CrossRef]

38. Garcia, K.R.; Rodrigues, L.; Pereira, L.; Busse, G.; Irbe, M.; Almada, M.; Christensen, C.; Midão, L.; Dias, I.; Heery, D.; et al. Improving the digital skills of older adults in a COVID-19 pandemic environment. Educ. Gerontol. 2021, 47, 196-206. [CrossRef]

39. Kinman, G.; Johnson, S. Special section on well-being in academic employees. Int. J. Stress Manag. 2019, 26, 159. [CrossRef]

40. Higher Education Statistics Agency. 'Who's Working in He? Personal Characteristics'. 2020. Available online: https://www.hesa. ac.uk/data-and-analysis/staff/working-in-he/characteristics (accessed on 2 October 2021).

41. Hughes, G.; Spanner, L. The University Mental Health Charter. Leeds: Student Minds. 2019. Available online: https://www. studentminds.org.uk/uploads/3/7/8/4/3784584/191208_umhc_artwork.pdf (accessed on 1 October 2021). 